\title{
Application of Thinking Exploration in Advertising Design and Teaching
}

\author{
Zuo Wei \\ Art Design Department \\ Hebei Vocational and Technical College of Building Materials \\ Qinhuangdao, China \\ e-mail:30799802@qq.com
}

\begin{abstract}
In order to let more workers be engaged in advertising design industry and get more design ideas in work, we introduce the notion of "expand thinking " in this article through advertising planning cases, case of teaching design and poster design case to illustrate the importance of thinking exploration in advertising design. Thinking exploration is a kind of divergent thinking. It is also called radiant thinking and fissile thinking. Think exploration conceives from different angles, directions and approaches to explore a variety of answers and ultimately solves problems satisfactorily. Application of thinking exploration in layout design makes the layout more vivid. Application of thinking exploration in poster design will make your designs more creative and more interesting. Thinking exploration is an effective mode of thinking in advertising design and teaching. The mastery of good thinking methods is the beginning of successful design. If we can master and make good use of thinking exploration, we will surely benefit a lot and achieve twice the result with half the effort in the future work and life.
\end{abstract}

Keywords: Thinking exploration; Advertising design; Teachinging

\section{INTRODUCTION}

Advertising design is an integrated discipline that refers to the painting art, computer software drawing, marketing and psychology. The learning of advertising design is unique. The emphasis of advertising design is to foster the practical operative abilities of students to engage in works in their fields and abilities to utilize the basic principles of visual communication to grasp the characteristics, creative methods and expression forms of different advertising medias, thus making students master the creative, designing and picture editing capabilities to design cultural, public and commercial advertising as well as the capacities to independently design commercial illustrations, print ads, brand planning, photography and new medias. According to the previous observations, many designers design immediately when they receive the design tasks according to their first inspiration. Subsequently, they just constantly improve the creative pictures and modify design details. They spend all their energy on the performance of works unnaturally. Consequently, the final design thought is narrow; designers can only carry out further improvement in one way. As a result, designers spend a lot of time and energy, but fail to design innovative works. Assuming designers are required to make several different designs with the same statement, they will fail to make an ideal work for insufficient design passion. In the current design industry, design is not only a kind of creative work; it is also a kind of repetitive work. The designer A works in an enterprise specializing in the design of plugs and sockets. Designers in that enterprise are required to design at least 5 kinds of new plugs each week. This seems to be few. However, in one year, at least 260 kinds of plugs and 52 kinds of sockets will be designed. If this situation continues for two or three years, or even a longer time, can you still complete the work while guaranteeing quality and quantity? Obviously, designs that rely on passion alone are not enough. We need a more rational thinking method that is able to continually create good ideas.

\section{APPLICATION OF THINKING EXPLORATION IN ADVERTISING CASES}

Thinking exploration is a kind of divergent thinking. It is also called radiant thinking and fissile thinking. Think exploration conceives from different angles, directions and approaches to explore a variety of answers and ultimately solves problems satisfactorily. Here we create an advertising design with divergent thinking. For example, we receive a work to design a television advertising for "NongFu Spring". Everyone knows the advertising slogan of NongFu Spring: "NongFu Spring, the sweet healthy water". Since the slogan has been well recognized by people, how to introduce a new advertisement and make it innovative and naturally accepted by the public? Obviously, this needs a lot of excellent and interesting creative ideas for final screening and modifying. At the same time, a valid mode of design thinking is particularly important.

First of all, we focus on the association of the four words "agriculture, famer, mountain and spring". We can associate the following three words with "agriculture": agriculture, rural area and farmer. We regard these three words as the first-tier keywords. We can associate the firsttier keyword "agriculture" with seeder, harvester, wheat field with ripe wheat, endless cornfield, etc. We can associate the first-tier keyword "rural area" with bungalow, firewood, muddy road, fowl, etc. We can associate the first-tier keyword "farmer" with dark skin, old straw hat, simple smiling face, etc. These keywords extending from 
the first-tier keywords are defined as the second-tier keywords. In this way, we can also find out the third-tier, the fourth-tier and even the Nth-tier keywords. For keywords in each tier, we can launch associations and create designs. The higher the tier of the keyword is, the more innovative the advertising is, as is shown in Fig.1. For example, we proceed from the keyword "farmer" and choose the second-tier keyword "simple smiling face", the third-tier keyword "wedding scene", the fourth-tier keyword "an ancient well" (there are red flowers representing good luck on the well) and the fifth-tier keyword "happy people who are drinking well water". We can complete an interesting advertising idea when we cascade these five keywords. Cascading keywords in different tiers in this way for screening, refining and modifying, a lot of good design ideas will be finally obtained, as is shown in Fig.2.

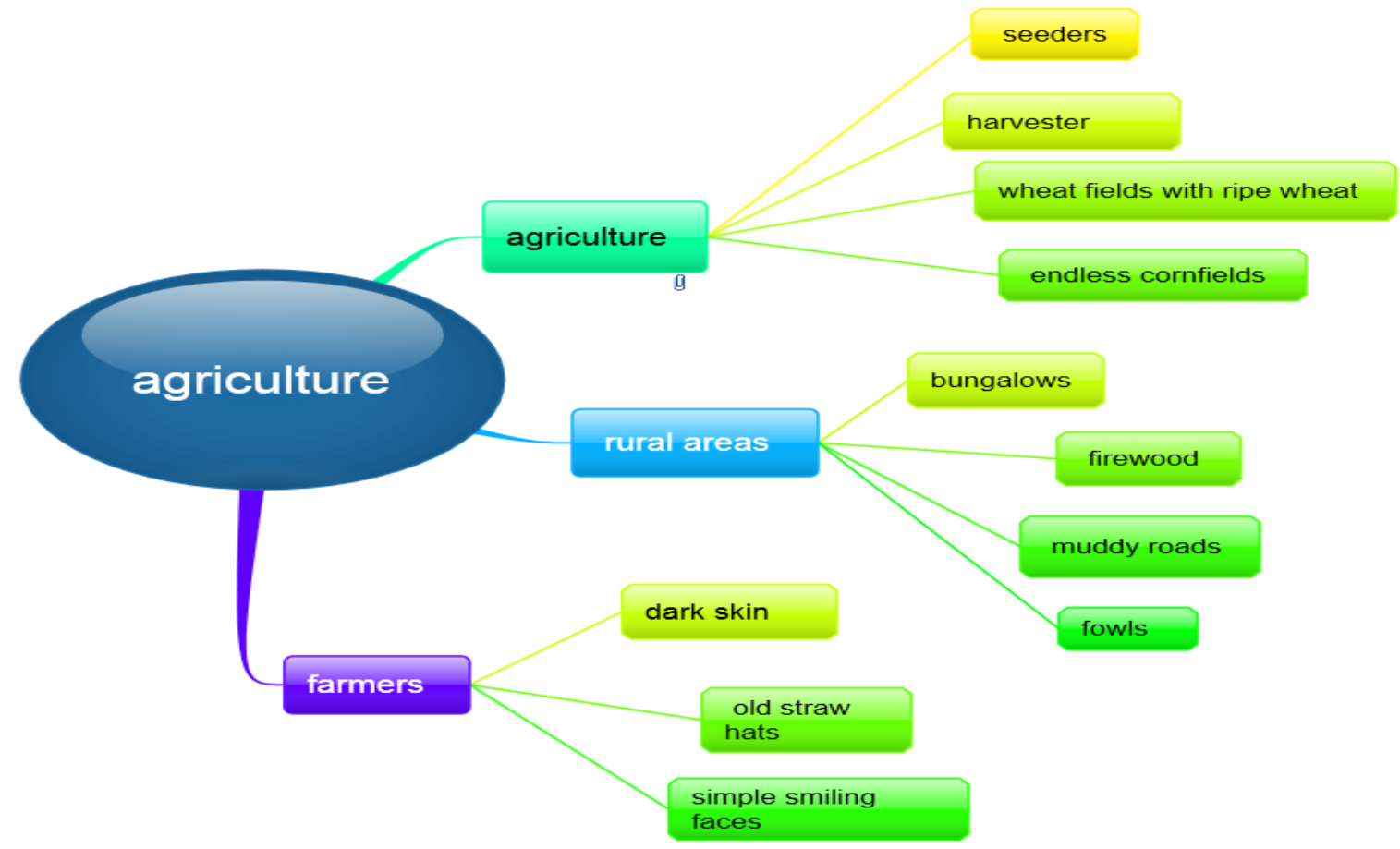

Figure 1. Thinking exploration tiers diagram

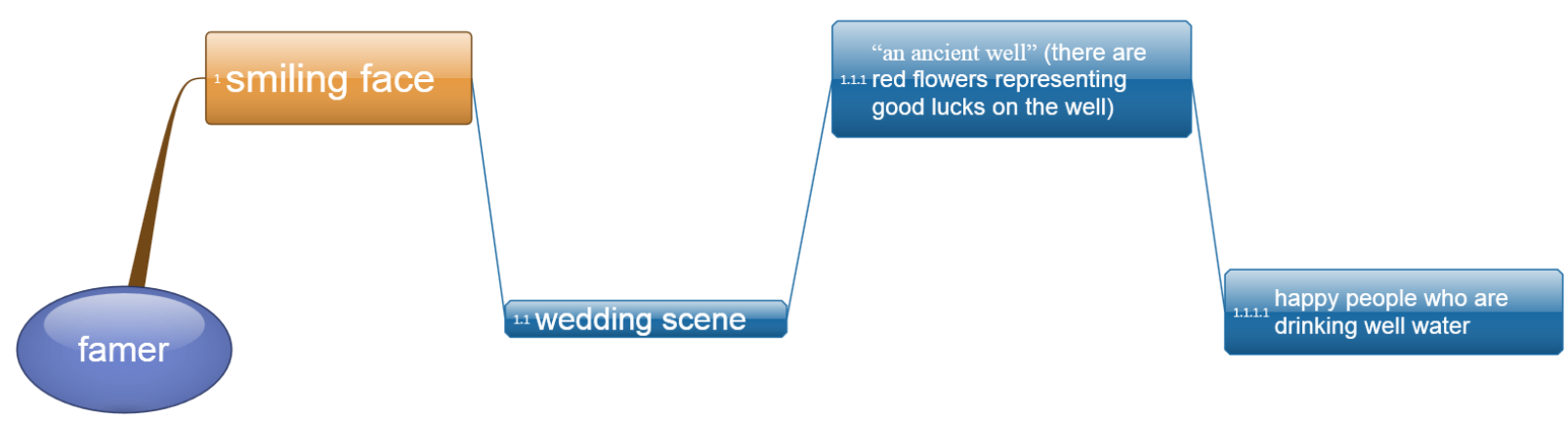

Figure 2. Tiers series diagram

\section{APPLICATION OF THINKING EXPLORATION IN DESIGN TEACHING}

Application of thinking exploration in layout design makes the layout more vivid. Confucius has said that: learning without thought is labor lost, while thought without learning is perilous. This means: learning without thinking will make people confused to get nothing while thinking without learning will make people tired to get nothing. From the sentence, we can clearly see the importance of thinking. There are a lot of combined exercises on the relationship among points, lines and surfaces in the previous design courses. Students are required to complete different picture effects via different combinations of forms. In the practical exercises, some students only make combinations via circles, squares and lines while some other students represent circles with apples, surfaces with plates and lines with knives and forks to make combinations. Obviously, pictures of the latter are more vivid than those of the former. However, there are some students who expand their thinking via divergent thinking principles to give points, lines and surfaces more interesting carriers. For example: representing lines with 
the sight of two persons who are looking at each other, surfaces with the smell of a delicious dish, points with the cross sections of a drop of water, etc.. It is obvious that thinking exploration can make your designs more vivid and interesting.

\section{APPLICATION OF THINKING EXPLORATION IN POSTER DESIGN}

Application of thinking exploration in poster design will make your designs more creative and more interesting. Whether it is topic poster, public poster or commercial poster, its core purpose is to convey information. Therefore, novel creativity is critical in the current society with excessive information to make your design concerned and approved by the audience at first sight. Take the poster design of the Olympic Games for example. When it comes to the Olympic Games, people soon associate it with the Olympic rings, torches, doves and medals. If we regard these elements as creative themes, it will be difficult to arouse the attention and interest of the audience. However, if we expand our thinking from these elements, the secondtier or third-tier design will become innovative and interesting. For example, associating medals with ribbons hanging medals and ribbons with the rainbow. The effect of regarding rainbow as the poster graphic design is obviously better than that of the medals.

\section{CONCLUSIONS}

Thinking exploration is an effective mode of thinking in advertising design and teaching. It can bring us inexhaustible design ideas. The mastery of good thinking methods is the beginning of successful design. If we can master and make good use of thinking exploration, we will surely benefit a lot and achieve twice the result with half the effort in the future work and life.

\section{REFERENCES}

[1] Zuo Wei, Dai You Jia. Plane advertisement design teaching experience in teaching[J]. Market Modernization, 2010, 8(620).

[2] Huang Xinchu, Zhang Xu. Poster desig[M]. Harbin: Engineering university press,2010, 2.

[3] Wang Hui. The contemporary Japanese poster design of visual semantic research $[\mathrm{J}]$. Nanjing: Journal of nanjing college of art, 2008, 3(177-180).

[4] Zheng Jun, Wu Kun. Poster design[M]. Shanghai: Shanghai Bookstore Publishing House, 2007.

[5] Xu Yang, Liu Ying. Layout and advertising design[M]. Shanghai: Shanghai People's Fine Art Publishing House, 2007.

[6] He Jianping. Matisse with his students[M]. Beijing: China Youth Publishing House, 2007.

[7] Forster, Fan Fei. Master poster design in the 21st century(Translation) [M]. Shanghai: Shanghai People's Fine Arts Publishing House, 2007.

[8] Lin Shiyan. Poster design[M]. Beijing: Tsinghua University Press, 2006.

[9] Liu Yumin, Lu Yang. Germany poster association in one hundred Europe's best poste(Translation)[M]. Shanghai: Shanghai Arts Publishing House, 2006.

[10] Lin Jiayang. Poster design[M]. Beijing: Higher Education Press, 2008. 